\section{RMD Open}

Rheumatic \&

Musculoskeletal Diseases

\title{
Probability-based algorithm using ultrasound and additional tests for suspected GCA in a fast-track clinic
}

Alwin Sebastian (D), ${ }^{1}$ Alessandro Tomelleri (D), ${ }^{1,2}$ Abdul Kayani, ${ }^{1}$ Diana PrietoPena, ${ }^{1,3}$ Chavini Ranasinghe, ${ }^{1}$ Bhaskar Dasgupta (D) 1

To cite: Sebastian A, Tomelleri $A$, Kayani $A$, et al. Probabilitybased algorithm using ultrasound and additional tests for suspected GCA in a fast-track clinic. RMD Open 2020;6:e001297. doi:10.1136/ rmdopen-2020-001297

- Supplemental material is published online only. To view please visit the journal online (http://dx.doi.org/10.1136/rmdo pen-2020-001297)

Received 30 April 2020 Revised 22 July 2020 Accepted 5 September 2020

Check for updates

(C) Author(s) (or their employer(s)) 2020. Re-use permitted under CC BY-NC. No commercial re-use. See rights and permissions. Published by BMJ.

${ }^{1}$ Rheumatology, Southend University Hospital NHS Foundation Trust, Westcliff-onSea, UK

2Unit of Immunology,

Rheumatology, Allergy and Rare Diseases, San Raffaele Scientific Institute, Milan, Italy

${ }^{3}$ Rheumatology, Marques de Valdecilla University Hospital, Santander, Spain

Correspondence to Bhaskar Dasgupta; bhaskar.das gupta@southend.nhs.uk

\section{ABSTRACT}

Objectives Clinical presentations of giant cell arteritis (GCA) are protean, and it is vital to make a secure diagnosis and exclude mimics for urgent referrals with suspected GCA. The main objective was to develop a joined-up, end-to-end, fasttrack confirmatory/exclusionary, algorithmic process based on a probability score triage to drive subsequent investigations with ultrasound (US) and any appropriate additional tests as required.

Methods The algorithm was initiated by stratifying patients to low-risk category (LRC), intermediate-risk category (IRC) and high-risk category (HRC). Retrospective data was extracted from case records. The Southend pretest probability score (PTPS) overall showed a median score of 9 and a 75th percentile score of 12 . We, therefore, classified LRC as PTPS $<9$, IRC 9-12 and HRC $>12$. GCA diagnosis was made by a combination of clinical, US, and laboratory findings. The algorithm was assessed in all referrals seen in 2018-2019 to test the diagnostic performance of US overall and in individual categories.

Results of 354 referrals, 89 had GCA with cases categorised as LRC (151), IRC (137) and HRC (66). 250 had US, whereas 104 did not (score $<7$, and/or high probability of alternative diagnoses). In HRC, US showed sensitivity $94 \%$, specificity $85 \%$, accuracy $92 \%$ and GCA prevalence $80 \%$. In LRC, US showed sensitivity undefined $(0 / 0)$, specificity $98 \%$, accuracy $98 \%$ and GCA prevalence $0 \%$. In IRC, US showed sensitivity $100 \%$, specificity $97 \%$, accuracy $98 \%$ and GCA prevalence $26 \%$. In the total population, US showed sensitivity $97 \%$, specificity $97 \%$ and accuracy $97 \%$. Prevalence of GCA overall was $25 \%$.

Conclusions The Southend PTPS successfully stratifies fast-track clinic referrals and excludes mimics. The algorithm interprets US in context, clarifies a diagnostic approach and identifies uncertainty, need for re-evaluation and alternative tests. Test performance of US is significantly enhanced with PTPS.

\section{INTRODUCTION}

Giant cell arteritis (GCA) is a critically ischaemic organ-threatening disease, ${ }^{12}$ particularly at the onset. Hence, it is vital to make a secure diagnosis urgently, not only to confirm GCA but also to exclude GCA mimics. ${ }^{3}{ }^{4}$ Several mimics, such as infection, cancer, head and neck pathology and systemic rheumatological

\section{Key messages}

What is already known about this subject?

- Vascular ultrasound is recommended as a first-line investigation in GCA, and pretest probability score (PTPS) is useful in stratifying the GCA referral patients into different categories.

What does this study add?

- The Southend PTPS successfully stratifies fast-track clinic GCA referral patients into low-risk, intermediaterisk and high-risk probability categories.

- The diagnostic algorithm includes ultrasound and additional tests, which help in the diagnostic approach. PTPS enhances test performance of US.

- Diagnostic uncertainty of GCA is identified as well as identifying which cases need further clinical reevaluation and helps choose additional tests.

How might this impact on clinical practice?

- This new diagnostic algorithm approach will allow having a faster and reliable triage and assessment of GCA referral patients (remote vs face-to-face review), and ongoing multicentre HAS GCA study will prospectively validate this algorithm.

diseases, are equally serious conditions with similar challenges for early diagnosis and treatment. ${ }^{5}$ In other less serious, chronic conditions such as non-specific headaches, migraine, fibromyalgia, neuralgia and spondylosis, it is important to avoid inappropriate empirical glucocorticoids (GC) and minimise GC side effects, while offering symptom alleviation, appropriate advice and therapy. ${ }^{6-8}$ Unfortunately, clinical presentations of GCA are protean, ${ }^{9}$ and they are often characterised by a mix of constitutional, cranial, ischaemic and polymyalgic symptoms combined with raised inflammatory markers, a clinical scenario that can be difficult to distinguish from symptoms and presenting features of other conditions. ${ }^{10}$ In particular, headache is 
a common but often misleading symptom experienced in GCA. ${ }^{11}$ Recent onset of headache, along with the presence of scalp tenderness and/or jaw claudication, may increase the likelihood of GCA. ${ }^{12}$ A non-specific response to empirical GC may compound this diagnostic conundrum, resulting in many patients with steroid-responsive headaches being mislabelled as GCA. ${ }^{13}$ American College of Rheumatology (ACR) 1990 GCA classification criteria $^{14}$ are often mistakenly used to diagnose GCA, but in clinical practice, they have low sensitivity and poor positive predictive value (PPV). ${ }^{1516}$

Fast-track GCA clinics (FTC) are gaining popularity to provide rapid specialist clinical assessment along with temporal and/or axillary ultrasound (US). ${ }^{4}{ }^{17}$ In GCA, they have been shown to reduce permanent sight loss. ${ }^{4}{ }^{17}$ EULAR recommendations support US as the first-choice diagnostic test, provided there are adequate expertise and equipment. ${ }^{18}$ Also, EULAR recommends using US or other cross-sectional imaging (eg, positron emission tomography (PET)-CT) to confirm the diagnosis of large-vessel vasculitis in suspected GCA. ${ }^{19}$ A logistical difficulty for FTC is the misconception of GCA as a 'headache disease', leading to the challenge of reducing non-specific headache referrals and enriching referrals of high-risk cases. ${ }^{4}$ We have previously reported a pretest probability score (PTPS) that shows promise to stratify patients into low-risk category (LRC), intermediate-risk category (IRC) and high-risk category (HRC) when first seen. ${ }^{20}$ Herein, we analyse our experience over 2 years (2018-2019) of pretest probability triage (with a primary US test and additional tests (AT) to follow), with the objective of describing a probability-based secure diagnostic algorithm that works in clinical practice. The main objective was to develop a joined-up, end-to-end, fast-track confirmatory/exclusionary, algorithmic process based on a probability score triage to drive subsequent investigations with US and any appropriate AT as required.

\section{METHODS}

Data records of all the patients referred to Southend Hospital FTC between January 1, 2018 and December 31, 2019 were retrospectively reviewed. For all the patients, the main clinical and laboratory features at referral were evaluated, and a PTPS was consequently generated (figure 1). PTPS in FTC was categorised into LRC, IRC and HRC based on the three quartiles $(\mathrm{Q} 1, \mathrm{Q} 2$ and Q3). After that, vascular US results, if performed, were reviewed (a vast majority of US were done within 1-2 working days, but GC treatment up to 1 week prior to US was allowed for this study). The application of the PTPS and the US results led us to categorise patients into four different categories ('GCA unlikely', 'GCA uncertain', 'treat as GCA with AT' and 'treat as GCA') which formed part of the diagnostic algorithm.

Final GCA diagnosis was confirmed after 6 months of follow-up and was made by fulfilling clinical criteria similar to Giant Cell Arteritis Actemra (GiACTA) trial criteria ${ }^{21}$ (see below). All GCA patients underwent at least one
Table I. GCA probability score [GCAPS] proforma.

\begin{tabular}{|c|c|c|c|c|c|}
\hline Weightage & -3 & 0 & +1 & +2 & +3 \\
\hline $\begin{array}{l}\text { Demographics } \\
\text { Age (years) } \\
\text { Sex }\end{array}$ & & $\leq 49$ & $\begin{array}{c}50-60 \\
\mathrm{M}\end{array}$ & $\begin{array}{c}61-65 \\
F\end{array}$ & $\geq 66$ \\
\hline $\begin{array}{l}\text { Duration } \\
\text { Onset of symptoms }\end{array}$ & & $>24$ weeks & 12-24 weeks & 6-12 weeks & $<6$ weeks \\
\hline $\begin{array}{l}\text { Laboratory } \\
\text { CRP }\end{array}$ & & $0-5 \mathrm{mg} / \mathrm{L}$ & $6-10 \mathrm{mg} / \mathrm{L}$ & $11-25 \mathrm{mg} / \mathrm{L}$ & $\geq 25 \mathrm{mg} / \mathrm{L}$ \\
\hline $\begin{array}{l}\text { Symptoms } \\
\text { Headache } \\
\text { Polymyalgic } \\
\text { Constitutional } \\
\text { Ischaemic }\end{array}$ & & $\begin{array}{l}\mathrm{N} \\
\mathrm{N} \\
\mathrm{N} \\
\mathrm{N}\end{array}$ & $\begin{array}{c}\mathrm{Y} \\
\text { Single }\end{array}$ & $\mathrm{Y}$ & $\begin{array}{c}\text { Combination } \\
\mathrm{Y}\end{array}$ \\
\hline $\begin{array}{l}\text { Signs } \\
\text { Visual (AION, CRAO, Field Ioss, RAPD) } \\
\text { TA abnormality } \\
\text { Extra-cranial artery abnormality } \\
\text { Cranial nerve paisy }\end{array}$ & & $\begin{array}{l}\mathrm{N} \\
\mathrm{N} \\
\mathrm{N} \\
\mathrm{N}\end{array}$ & $\begin{array}{l}\text { Tendemess } \\
\text { Thickening }\end{array}$ & $\begin{array}{l}\text { Thickening } \\
\text { Bruit }\end{array}$ & $\begin{array}{l}\text { Y } \\
\text { Pulse loss } \\
\text { Pulse loss } \\
\text { Y }\end{array}$ \\
\hline $\begin{array}{l}\text { Alternative } \\
\text { Infection } \\
\text { Cancer } \\
\text { Systemic Rheumatic diseases } \\
\text { Head and neck pathology } \\
\text { Other } \\
\text { Total score }\end{array}$ & $\begin{array}{l}\mathrm{Y} \\
\mathrm{Y} \\
\mathrm{Y} \\
\mathrm{Y} \\
\mathrm{Y}\end{array}$ & & & & \\
\hline
\end{tabular}

Figure 1 Southend giant cell arteritis (GCA) probability score (adapted from Laskou et $\mathrm{al}^{20}$ ). AION, anterior ischemic optic neuropathy; CRAO, central retinal artery occlusion; CRP, C-reactive protein; RAPD, relative afferent pupillary defect; TA temporal artery.

imaging evaluation-US and/or PET-CT—or a temporal artery biopsy (TAB) to confirm clinical suspect. Majority of the patients were seen in the FTC on the same day as the referral or the next working day. Most of them were commenced on 40-60 mg oral prednisolone by their general practitioners at the time of the referral. The non-GCA diagnoses were all confirmed at 6 months.

\section{Clinical criteria}

- Age $\geq 50$ years.

- Erythrocyte sedimentation rate $(\mathrm{ESR})>30 \mathrm{~mm} / \mathrm{h}$ or Creactive protein $(\mathrm{CRP})>5 \mathrm{mg} / \mathrm{L}$.

- Unequivocal cranial symptoms of GCA or symptoms of polymyalgia rheumatica (PMR).**

- Abnormal temporal artery (TA) (US or biopsy) or evidence of large-vessel vasculitis by US or crosssectional imaging (eg, PET-CT and CT angiography).

*CRP and ESR measurements done before the treatment.

**Cranial symptoms defined as new, localised head pain, generalised scalp tenderness, tender TA, ischaemic optic neuropathy, jaw claudication or tongue claudication. PMR symptoms defined as morning stiffness $>1$ hour with bilateral shoulder pain and/or bilateral hip pain or stiffness.

\section{Imaging of temporal and axillary arteries}

US scans were performed or supervised by an experienced ultrasonographer (BD) with an Esaote MyLabTwice US machine. A linear probe (LA435) with greyscale frequency of $18 \mathrm{MHz}$ or $22 \mathrm{MHz}$ and colour doppler frequency of $9 \mathrm{MHz}$ was used. The pulse repetition frequency was $2-3 \mathrm{kHz} .{ }^{18}$ The common superficial TA and their parietal and frontal branches, and/or the axillary 
arteries (AA) were examined in the long and short axes. Halo was measured at the point of maximum thickness in the longitudinal plane. A halo sign was morphologically defined as a US finding of a dark hypoechoic, noncompressible area around the vessel lumen. ${ }^{22-25}$ An abnormal vessel wall thickness was defined as $>0.29-0.42 \mathrm{~mm}$ in TA segments and $>1.0 \mathrm{~mm}$ in AA. ${ }^{26}$ The TA halo score was determined, as recently described. ${ }^{27}$ In addition, a provisional AA halo score was determined.

\section{Data analysis}

The results were expressed as the means $\pm \mathrm{SD}$ or as percentages. Descriptive statistics for test performance, twotailed Fisher's exact test, Mann-Whitney U-test and KruskalWallis test were used for statistical analysis. All calculations were performed using SPSS statistical software. A p value $<0.05$ was considered statistically significant. Sensitivity, specificity, PPV, negative predictive value (NPV), likelihood ratios, prevalence and accuracy were calculated.

\section{RESULTS}

\section{Demographics}

Between January 1, 2018 and December 31, 2019, 371 consecutive patients were evaluated in Southend GCA FTC. Seventeen patients were excluded due to incomplete data (tertiary referrals from other hospitals). Of the remaining 354 patients with complete data available, $89(25 \%)$ eventually received a diagnosis of GCA. Mean age of the patients at the time of referral was 71.6 \pm 0.81 years, and $69 \%$ of them were women.

\section{Pretest probability score and algorithm}

PTPS in FTC patients overall showed a median (Q2) score of 9 and a 75th percentile (Q3) score of 12. Based on this (and on previous PTPS reported cut-off of $9.5^{20}$ ), LRC was classified as PTPS $<9$, IRC as PTPS 9-12 and HRC as PTPS $>12$ (figure 2). After the application of the PTPS, patients were categorised as LRC (151, 43\%), IRC (137, $39 \%$ ) and HRC $(66,18 \%)$. In our algorithm, PTPS along with US results allowed us to further categorise referred cases into four different groups: 'GCA unlikely' (233), 'GCA uncertain' (24) 'treat as GCA with AT' (23) and 'treat as GCA' (74) (AT not necessary) (figure 3).

The 'GCA unlikely' group (online supplemental figure S1) represented cases with negative US (or US not done) and for whom no other AT was considered necessary. The 'treat as GCA' group (online supplemental figure S2) included patients in HRC (45) or IRC (28) who had an unequivocal positive US. We identified two groups with diagnostic uncertainty (ie, the groups 'GCA uncertain' and 'treat as GCA with AT and/or clinical re-evaluation') (online supplemental figure S3, S4). The former group 'GCA uncertain' (24 cases) came from US-negative IRC (11), US-positive IRC (1) but also from US-positive (3) and US-negative/not done (6) LRC, and from a few USnegative HRC (3). The group 'treat as GCA with AT' came entirely from the HRC (12) and IRC (11) groups.

\section{CATEGORIES VS PROBABILITY SCORE}

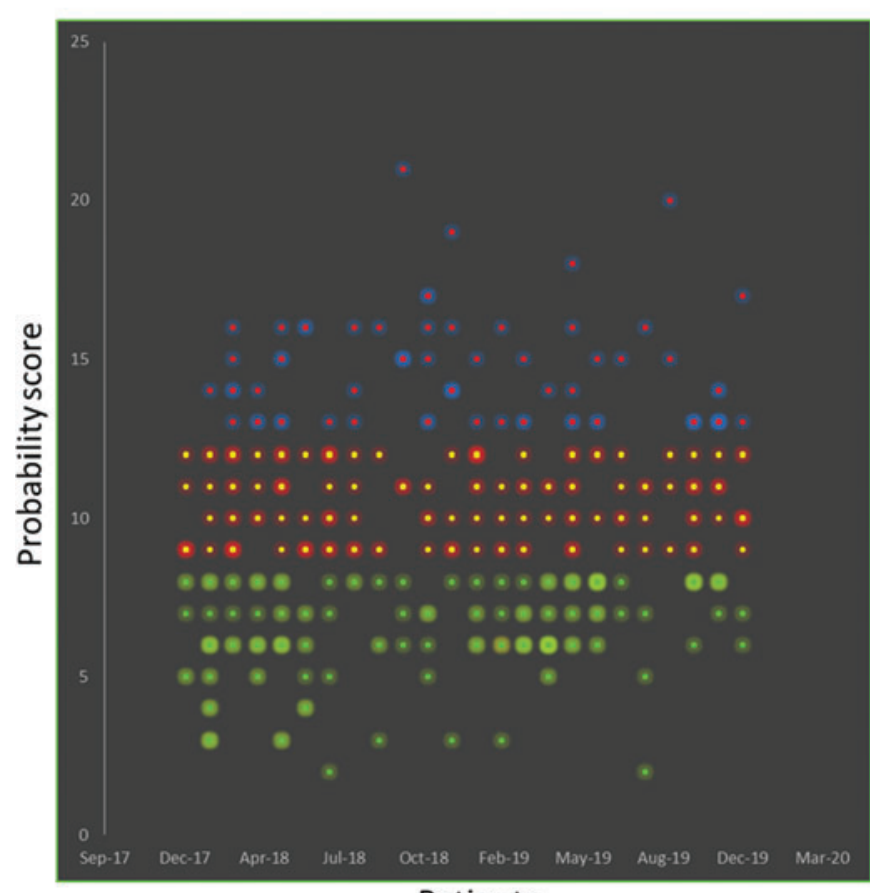

Patients

Figure 2 Categories according to the probability score.

\section{Clinical features}

Table 1 shows the main clinical features at the time of referral. Interestingly, the generalised, non-localised headache was higher in LRC patients, whereas temporal headache (unilateral or bilateral) was more common in HRC patients. Not surprisingly, CRP level and frequency of scalp tenderness, jaw claudication, polymyalgic symptoms and constitutional symptoms (eg, night sweats, weight loss and fever) were significantly higher in HRC

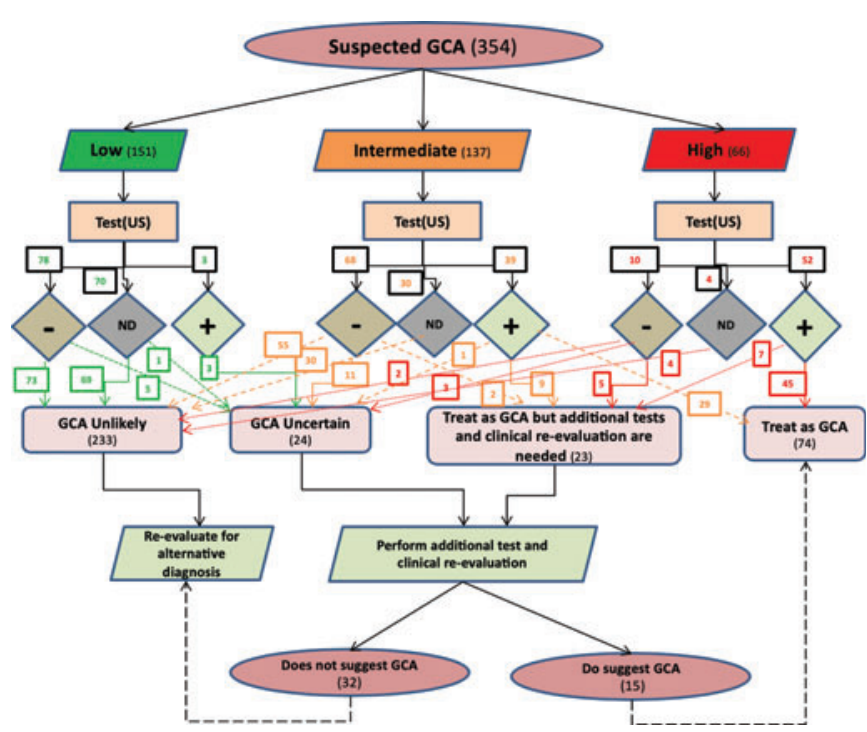

Figure 3 Probability-based diagnostic algorithm for suspected giant cell arteritis (GCA). US, ultrasound. 
Table 1 Main clinical signs and symptoms at GCA fast-track clinic referral

\begin{tabular}{|c|c|c|c|c|c|c|c|c|}
\hline & $\begin{array}{l}\text { Total no. } \\
354(\%)\end{array}$ & $\begin{array}{l}\text { LRC no. } \\
151(\%)\end{array}$ & $\begin{array}{l}\text { IRC no. } \\
137(\%)\end{array}$ & $\begin{array}{l}\text { HRC no. } \\
66(\%)\end{array}$ & $P$ value & $\begin{array}{l}\text { Not GCA } \\
\text { no. } 265(\%)\end{array}$ & $\begin{array}{l}\text { GCA no. } \\
89(\%)\end{array}$ & $P$ value \\
\hline \multicolumn{9}{|l|}{ Headache } \\
\hline Generalised & $56(15.8)$ & $31(20.5)$ & $21(15.3)$ & $4(6.1)$ & 0.02 & $53(20)$ & $3(3.4)$ & 0.002 \\
\hline $\begin{array}{l}\text { Temporal, } \\
\text { unilateral }\end{array}$ & $110(31.1)$ & $41(27.2)$ & $43(31.4)$ & $26(39.4)$ & 0.2 & $73(27.5)$ & $37(41.6)$ & 0.01 \\
\hline $\begin{array}{l}\text { Temporal, } \\
\text { bilateral }\end{array}$ & $73(20.6)$ & $20(13.2)$ & $31(22.6)$ & $22(33.3)$ & 0.003 & 38 (14.3) & 35 (39.3) & $<0.001$ \\
\hline \multicolumn{9}{|l|}{ Scalp tenderness } \\
\hline Unilateral & $53(15)$ & $14(9.3)$ & $19(13.9)$ & $20(30.3)$ & 0.001 & $26(9.8)$ & $27(30.3)$ & $<0.001$ \\
\hline Bilateral & $51(14.4)$ & $11(7.3)$ & $16(11.7)$ & $22(33.3)$ & $<0.001$ & $22(8.3)$ & 29 (32.6) & $<0.001$ \\
\hline Jaw claudication & $70(19.8)$ & $11(7.3)$ & $25(18.2)$ & 34 (51.5) & $<0.001$ & $23(8.7)$ & 47 (52.8) & $<0.001$ \\
\hline PMR symptoms & $134(37.9)$ & 38 (25.2) & $61(44.5)$ & $35(53)$ & $<0.001$ & $93(35.1)$ & $41(46.1)$ & 0.043 \\
\hline \multicolumn{9}{|c|}{ Constitutional symptoms } \\
\hline Single & $63(17.8)$ & $18(11.9)$ & $24(17.5)$ & $21(31.8)$ & 0.003 & $37(14)$ & $26(29.2)$ & 0.001 \\
\hline Combination & $50(14.1)$ & $6(4)$ & $22(16.1)$ & $23(34.8)$ & $<0.001$ & $25(9.4)$ & $26(29.2)$ & $<0.001$ \\
\hline \multicolumn{9}{|c|}{ Visual disturbances } \\
\hline Blurred vision & $62(17.5)$ & 19 (12.6) & $23(16.8)$ & $20(30.3)$ & 0.008 & $36(13.6)$ & $26(29.2)$ & 0.001 \\
\hline Double vision & $17(4.8)$ & $5(3.3)$ & $7(5.1)$ & $5(7.6)$ & 0.352 & $9(3.4)$ & $8(9)$ & $<0.001$ \\
\hline Amaurosis & $22(6.2)$ & $4(2.6)$ & $9(6.6)$ & $9(13.6)$ & 0.01 & $8(3)$ & $14(15.7)$ & $<0.001$ \\
\hline \multicolumn{9}{|l|}{ Vision loss type } \\
\hline AION & $16(4.5)$ & $1(0.7)$ & $5(3.6)$ & $10(15.1)$ & $<0.001$ & $2(0.8)$ & $14(15.7)$ & $<0.001$ \\
\hline CRAO & $8(2.3)$ & $1(0.7)$ & $4(2.9)$ & $3(4.5)$ & 0.126 & $3(1.1)$ & $5(5.6)$ & 0.026 \\
\hline $\mathrm{AION}+\mathrm{CRAO}$ & $3(0.8)$ & 0 & $2(1.5)$ & $1(1.5)$ & 0.308 & 0 & $3(3.4)$ & 0.015 \\
\hline $\begin{array}{l}\text { Mean CRP level } \\
\text { (mg/L) }\end{array}$ & $38( \pm 51)$ & $15( \pm 25)$ & $42( \pm 50)$ & $82( \pm 64)$ & $<0.001$ & $28( \pm 45)$ & $68( \pm 56)$ & $<0.001$ \\
\hline
\end{tabular}

AION, anterior ischaemic optic neuritis; CRAO, central retinal artery occlusion; CRP, C reactive protein; GCA, giant cell arteritis; HRC, high-risk category; IRC, intermediate-risk category; LRC, low-risk category; PMR, polymyalgia rheumatica.

patients and then in those eventually diagnosed with GCA. Notably, blurred vision was the most common visual disturbance among HRC patients. Overall, all the GCA symptoms and signs showed an increase through LRC, IRC to HRC, except for generalised headache.

\section{Ultrasound results}

US of the TA and/or AA was performed in a total of 250 patients $(71 \%)$, and the results were positive in $3 / 151$ LRC (2\%), in 39/137 IRC (29\%) and in 52/66 HRC (79\%) patients. Overall, in the totality of the FTC population, US sensitivity was $97 \%$, specificity $97 \%$ and accuracy $97 \%$.

\section{High-risk category}

Of the 52 US-positive HRC patients, 45 were treated as GCA without the need of AT, while 7 were investigated with AT while receiving treatment for GCA. Of these, only two patients were eventually diagnosed as non-GCA. Of the 10 US-negative HRC patients, 3 (30\%) were subsequently diagnosed with GCA but only after AT (PET-CT, 2; $\mathrm{TAB}, 1)$. In four patients, the clinical presentation was so typical of PMR without GCA and urgent for therapy that delays for US or AT to confirm the diagnosis was considered inappropriate. The total number of GCA and non-GCA in this category was 53 and 13, respectively. As a consequence, the sensitivity of US in HRC was $94 \%$, specificity was $85 \%$ and accuracy was $92 \%$ (see tables $2-3$ for details).

\section{Intermediate-risk category}

US was positive in 39 IRC patients, and, of these, 27 (69\%) were diagnosed without the need of AT. Twelve patients had AT and in only three of them (8\%) GCA diagnosis was not confirmed after AT. Interestingly, none of the 68 IRC patients with the negative US was subsequently diagnosed as GCA ( 13 of them required AT). The total number of GCA and non-GCA in this category was 36 and 101, respectively. Regarding the performance of the US in IRC, sensitivity was $100 \%$, specificity $97 \%$ and accuracy $98 \%$.

\section{Low-risk category}

Only three LRC patients had positive US. However, they were not treated as GCA but subsequently underwent AT, which pointed to other diagnoses. In 70 LRC patients, US was not done because the suspicion of GCA was too low. In total, GCA prevalence in this group was $0 \%$. Therefore, 


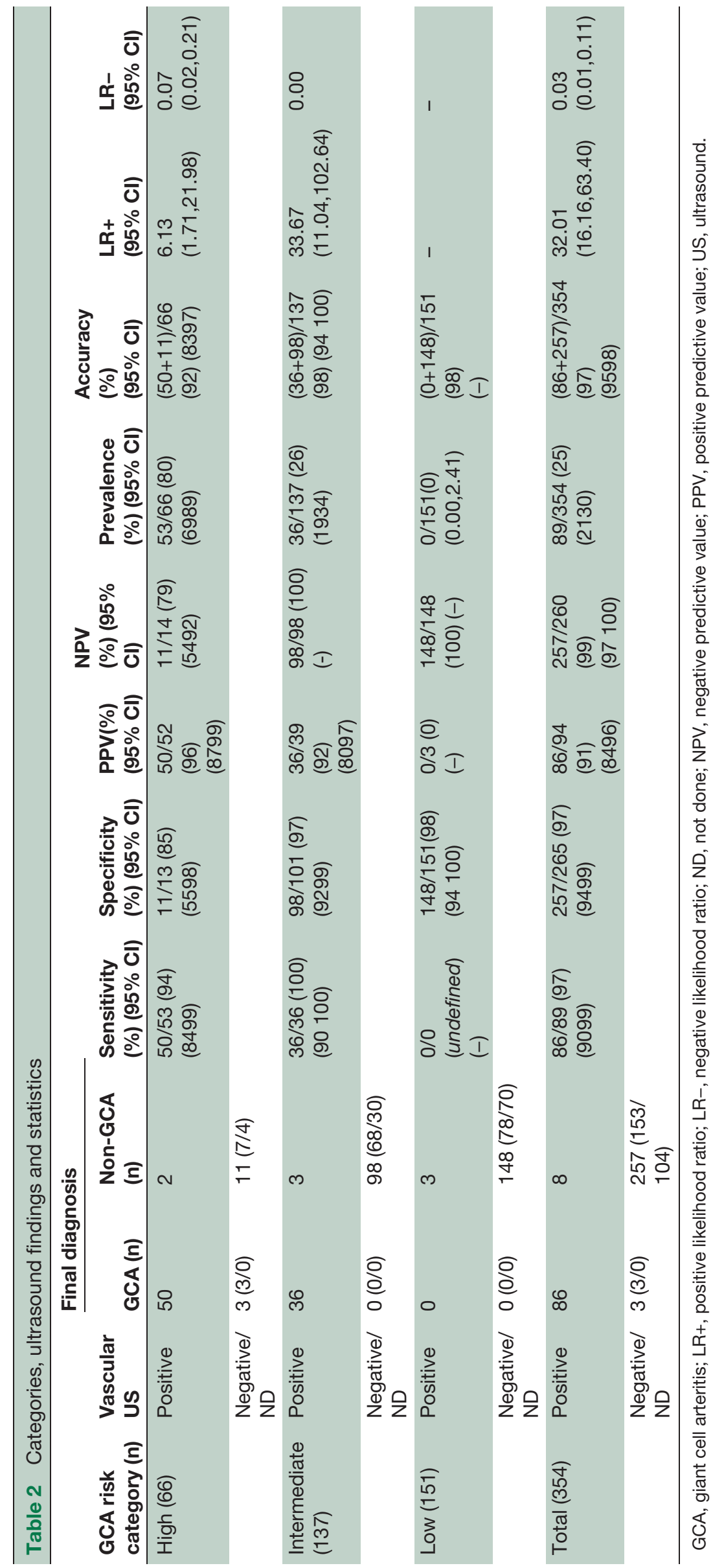




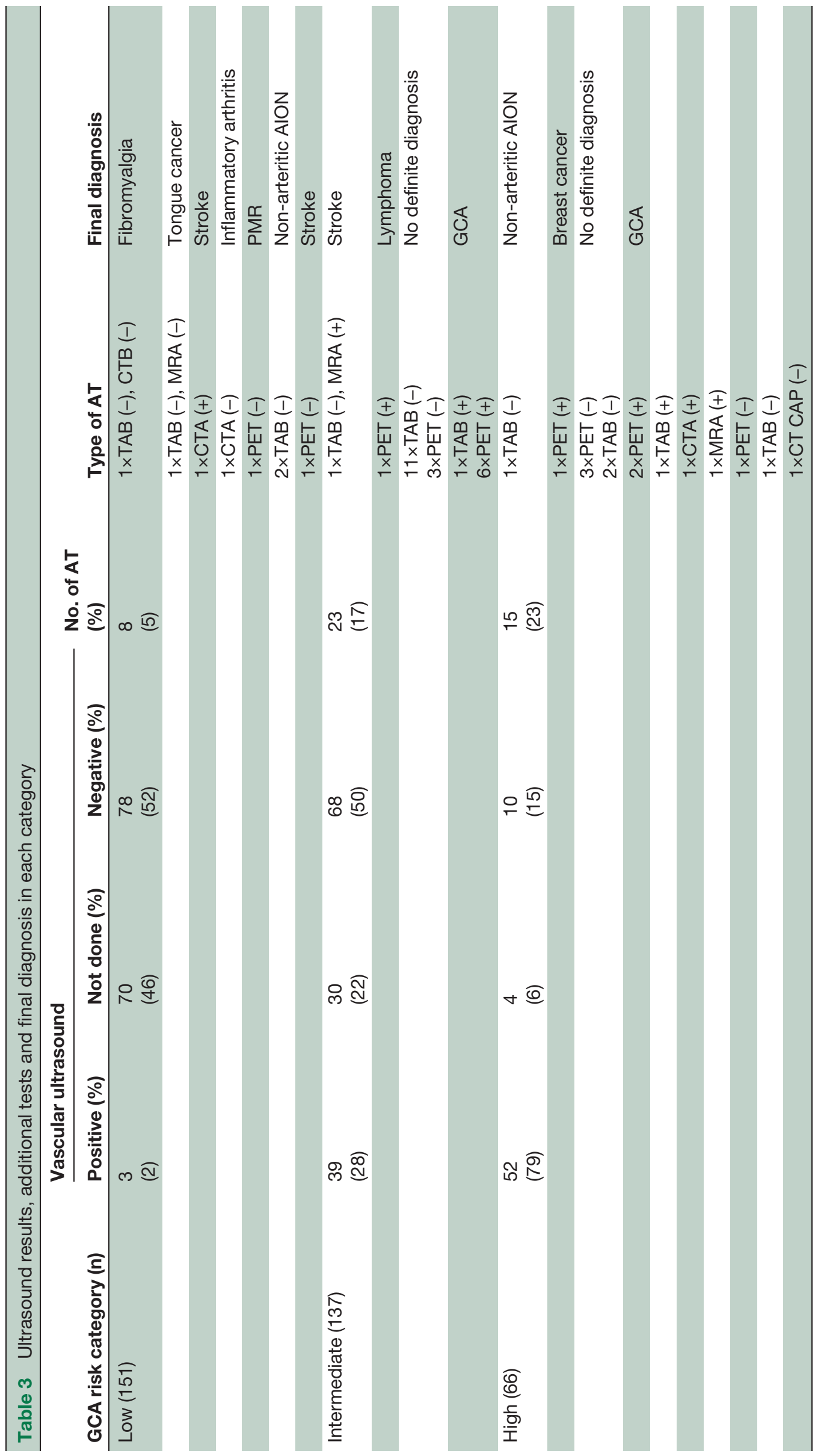

这

ठั

는응

.

흉

比交

产皇

空亏

흉

응 응

등

宁索

达

응

is है

变

을

흥 승

造

is

돟

ब.

응 응

을 음

đ음

总

흔

壱

뜧ำ

근 
in LRC patients, US had extremely high specificity (98\%) and accuracy (98\%) (see tables 2-3 for details).

\section{DISCUSSION}

This single-centre 2-year cohort study of referrals to the FTC suggests that cases with suspected GCA represent a continuum of probability for GCA and that the Southend PTPS successfully stratifies them to HRC, IRC and LRC. This allows the diagnostic algorithm (with the US as the initial test and AT as required) to confirm GCA and securely exclude non-GCA. The overall prevalence of GCA over 2 years was $25 \%$. However, the prevalence of GCA rose satisfactorily through the various pretest probability groups (LRC, 0\%; IRC, 24\%; HRC, 80\%). We, therefore, feel that this algorithm successfully stratifies suspected GCA referrals for the US and AT and simplifies the diagnostic approach. It also validates our cut-offs for the three probability groups categorised based on probability scores obtained overall for the entire 2-year referrals. ${ }^{20}$ Any score above Q3 (>75th percentile, ie, $>12$ ) was HRC, between Q2 and Q3 (50th-75th percentile, ie, 9-12) was IRC and less than Q2 (<50th percentile, ie, <9) was LRC. We have considered in future of adding a very low category below $\mathrm{Q} 1(<25$ th percentile, ie, score $<7)$ but this is not the subject of the current study. We are pleased our current definitions fit well with the cut-off of 9.5, dividing LRC from IRC and HRC (ie, LRC is $<9$ ) reported from the original study. ${ }^{20}$

The test performance of US in GCA was considerably enhanced with this Bayesian probability-based approach, as sensitivity, specificity, PPV and NPV of US overall and in all categories were much higher than previously reported (sensitivity in LC was undefined since there were no false negatives) ${ }^{29} \mathrm{We}$ feel such a pretest Bayesian approach markedly augments the diagnostic performance of a test such as US and forms the rational basis for planning AT based on progress through the algorithm. Such an approach could be successfully implemented in other rheumatological areas such as in early arthritis clinics, where the assessment of pretest probability of early inflammatory arthritis (EIA) referrals may allow better planning of the assessment/investigative approach using US and ancillary tests. ${ }^{28}$

We are aware that in this study the result of US was dichotomous (ie, 'halo sign positive' vs 'halo sign negative'). Currently, we are investigating the use of a quantitative US score (ie, Southend Halo Score ${ }^{27}$ ) in a prospective study (the 'HAS-GCA study ${ }^{30}$ ) to see whether a quantitative approach that ascertains extent and severity of US GCA lesions may further enhance the test performance of US. There is preliminary evidence that indeed this is so. This too has implications for the use of musculoskeletal US in inflammatory arthritis. There is evidence that using a quantitative analysis of doppler US along with clinical features may potentially replace the necessity of TAB in GCA, especially in the current pandemic environment where invasive tests in a hospital environment may not be popular with patients. ${ }^{31}$

In the 151 cases in LRC, the prevalence of GCA was $0 \%$, and 70 cases did not even require the US. Of the 81 cases who had the US, 78 were negative. Although three were interpreted as US-positive, they were not started on steroids, and further investigations failed to confirm the diagnosis. Based on our results, we feel that the LRC may not require a face-to-face review in a specialist clinic, provided the probability score is accurately computed by a trained assessor. This could be performed by a trained clinician (a doctor or a nurse) through a telephone clinic. In the current climate of a global viral pandemic, this approach with prior ascertainment of pretest probability of a referral will significantly weigh the decision to proceed with remote consultation, assessment and advice given to the patient and referring physician versus the need for a face-to-face consultation.

We acknowledge that not all the patients had the US at the initial evaluation, and they were included in the USnegative/not done category. This may give a potential bias (ie, HRC specificity drops from $85 \%$ to $78 \%$ with only a slight drop in IRC and LRC). Online supplemental table 1 outlines these figures in detail. Nevertheless, these patients remained non-GCA after 6 months.

With respect to the four diagnostic categories (GCA unlikely, GCA uncertain, treat as GCA with AT and treat as GCA), the 'GCA unlikely' group (online supple mental figure S1) reduces follow-up where a structured clinical assessment and PTPS, along with the point of care US, lead to a rapid and definitive decision to allow patient and physician education, reassurance and search for alternative pathology. The 'treat as GCA' group (online supplemental figure S2) was also populated as a one-stop decision (ie, patients in HRC or IRC who had an unequivocal positive US). We are currently working on what that unequivocal positive US is, whether quantitative halo score (Southend Halo Score) gives better test performance to decide on immediate treatment. There is evidence that larger and more extensive halos may be associated with more severe disease such as ocular ischaemia. ${ }^{27}$ Our algorithm also allows precise identification of uncertainty (ie, 'GCA uncertain' and 'treat as GCA with AT and/or clinical re-evaluation') (online supplemental figure S3, S4). 'GCA uncertain' group requires AT such as PET$\mathrm{CT}, \mathrm{TAB}$ or investigations for other pathology while withholding GC for GCA. We feel the quantitative Southend Halo Score would have reduced this uncertainty which arose not only related to the post-test probability of GCA but also to the probability of alternative pathology and individual safety of GC therapy in view of demographics, patient-specific factors, risks and comorbidities. The algorithm again contributes to the patient management and review strategy (face-to-face vs remote reviews). The 'treat as GCA with AT' group emphasises that the priorities about urgently treating GCA were balanced against individual patient factors, 
US findings and the probability of an alternative diagnosis. This group mostly generated the AT, such as TAB in suspected cranial GCA and PET-CT in suspected large-vessel GCA. Overall, only nine TAB were requested over these 2 years, perhaps reinforcing the success of this approach.

A major objective of the FTC is that it speedily diagnoses non-GCA serious pathology too. Hence, our probability score can allow inclusion of other serious mimics of GCA (as alternative diagnosis) which are rapidly confirmed with appropriate AT if US is negative, equivocal or discordant with clinical clues. Making a diagnosis in the HRC of GCA in $80 \%$ of patients with related US specificity of $85 \%$ reflects the fact that our keenness to make a correct diagnosis of GCA in this group is matched by an equal desire not to miss a non-GCA serious mimic such as head and neck cancer, infection or systemic rheumatological disease.

We feel that this probability-based approach for GCA diagnosis can be successfully considered in other areas of rheumatology. In particular, it should apply very well to EIA clinics. The critical aspect of the Southend PTPS is the negative weightage for alternative causative factors, and in a score for an EIA clinic, this should include other causes of musculoskeletal pain, such as osteoarthritis, fibromyalgia and systemic connective tissue diseases. The role of targeted point of care US also becomes enhanced with higher diagnostic test performance, and the inclusion of quantitative musculoskeletal US assessments ${ }^{32}$ should have an enhancing effect. The EIA algorithm will then allow us to arrive at analogous decision points (ie, 'EIA unlikely', 'EIA uncertain', 'treat as EIA' or 'treat as EIA with AT').

This approach should be more cost-effective since it reduces the requests for invasive and expensive tests, such as TAB and PET-CT, respectively. The skill required to perform a $\mathrm{TAB}$, the disincentive of an invasive test and the cost and waiting time of a PET-CT are currently ongoing challenges in the UK. It makes the diagnosis of alternative pathology more rapid and should enable higher patient satisfaction, education, reassurance as well as immediate treatment of GCA after speedy diagnostic confirmation.

A similar approach could also be used for follow-up of GCA patients. It would be extremely useful for clinicians to have a score which comprises both clinical and laboratory findings and that can help them to adequately categorise patients already diagnosed with GCA and to guide them in their management (eg, reduction/increase of GC, the addition of steroid-sparing agents and request of diagnostic tests). We are currently working on a GCA clinical activity proforma and, in order to maintain a homogeneous approach, we think that this activity score should be used to assign GCA patients to the same four categories of the Southend PTPS (ie, 'active GCA unlikely', 'active GCA uncertain', 'treat as active GCA' and 'treat as active GCA with AT'). This novel scoring system would be helpful to guide clinicians not only in their daily practice but also when treating patients in the setting of clinical trials, as it would guarantee more uniform management between different centres. Our ongoing multicentre HAS GCA study with forming a halo score based on the intimal medial thickness measurement of the TA and AA will further support our diagnostic algorithm.

We feel our novel approach to GCA is fully validated by our 2-year experience, although we acknowledge that this is indeed a single-centre, open experience. Be that as it may, there may be an even greater need for rapidly adopting this approach across other diseases, especially during the current global viral pandemic crisis, since it arrives quickly at the decision between face-to-face versus remote review.

Twitter Bhaskar Dasgupta @profbdasgupta.

Acknowledgements All authors would like to thank the Research and Development department at Southend University Hospital.

Contributors AS, AT and BD contributed to the conception or design of the work. $A T, A K, D P-P, C R$ and $B D$ contributed to acquisition of data including ultrasound scans which were all done or personally supervised by BD. AS, AT and BD contributed to the analysis or the interpretation of data. All authors were involved in drafting the work or revising it critically for relevant intellectual content. All authors provided final approval of the version published.

Funding AS received an international educational (Bresnihan-Molloy) fellowship grant from the Royal College of Physicians of Ireland.

Competing interests $B D$ reports grants and personal fees from Roche, personal fees from GSK, BMS, Sanofi and Abbie, outside the submitted work. All other authors have nothing to declare.

Patient consent for publication Not required.

Ethics approval This is a retrospective study where Research Ethics Committee approval is not required according to the local ethics guidelines.

Provenance and peer review Not commissioned; externally peer reviewed.

Data availability statement All data relevant to the study are included in the article or uploaded as supplemental information.

Supplemental material This content has been supplied by the author(s). It has not been vetted by BMJ Publishing Group Limited (BMJ) and may not have been peerreviewed. Any opinions or recommendations discussed are solely those of the author(s) and are not endorsed by BMJ. BMJ disclaims all liability and responsibility arising from any reliance placed on the content. Where the content includes any translated material, BMJ does not warrant the accuracy and reliability of the translations (including but not limited to local regulations, clinical guidelines, terminology, drug names and drug dosages), and is not responsible for any error and/or omissions arising from translation and adaptation or otherwise.

Open access This is an open access article distributed in accordance with the Creative Commons Attribution Non Commercial (CC BY-NC 4.0) license, which permits others to distribute, remix, adapt, build upon this work non-commercially, and license their derivative works on different terms, provided the original work is properly cited, appropriate credit is given, any changes made indicated, and the use is non-commercial. See: http://creativecommons.org/licenses/by-nc/4.0/.

\section{ORCID iDs}

Alwin Sebastian http://orcid.org/0000-0002-9562-6748

Alessandro Tomelleri http://orcid.org/0000-0002-5440-2078

Bhaskar Dasgupta http://orcid.org/0000-0002-5523-6534

\section{REFERENCES}

1 Soriano A, Muratore F, Pipitone N, et al. Visual loss and other cranial ischaemic complications in giant cell arteritis. Nat Rev Rheumatol 2017;13:476-84.

2 Caselli RJ, Hunder GG. Neurologic complications of giant cell (temporal) arteritis. Semin Neurol 1994;14:349-53.

3 Buttgereit F, Dejaco C, Matteson EL, et al., Polymyalgia rheumatica and giant cell arteritis a systematic review. JAMA 2016;315:2442-58. 
4 Patil P, Williams M, Maw WW, et al. Fast track pathway reduces sight loss in giant cell arteritis: results of a longitudinal observational cohort study. Clin Exp Rheumatol 2015.

5 Smetana GW, Shmerling $\mathrm{RH}$, Does this patient have temporal arteritis? J Am Med Assoc 2002;287:92-101.

6 Proven A, Gabriel SE, Orces C, et al., Glucocorticoid therapy in giant cell arteritis: duration and adverse outcomes. Arthritis Rheum 2003;49:703-8.

7 Wilson JC, Sarsour K, Collinson N, et al. Serious adverse effects associated with glucocorticoid therapy in patients with giant cell arteritis (GCA): a nested case: control analysis. Semin Arthritis Rheum 2017:46:819-27.

8 Coath F, Gillbert K, Griffiths B, et al. Giant cell arteritis: new concepts, treatments and the unmet need that remains. Rheumatology (UK) 2019;58:1123-5.

9 de Boysson $\mathrm{H}$, Liozon E, Ly KH, et al. The different clinical patterns of giant cell arteritis. Clin Exp Rheumatol 2019.

10 Dejaco C, Brouwer E, Mason JC, et al. Giant cell arteritis and polymyalgia rheumatica: current challenges and opportunities. Vol. 13. Nature Reviews Rheumatology. Nature Publishing Group, 2017: 1-15.

11 Tuckwell K, Collinson N, Dimonaco S, et al. Newly diagnosed vs. relapsing giant cell arteritis: baseline data from the GiACTA trial. Semin Arthritis Rheum 2017;46:657-64.

12 Headache Classification Committee of the International Headache Society (IHS) The International Classification of Headache Disorders. 3rd edn. Cephalalgia: Sage Publications Ltd. 2018

13 AJ S. Diagnosis and management of headache in older adults. Mayo Clin Proc 2018;93:252-62.

14 Hunder GG, Bloch DA, Michel BA, et al. The American College of Rheumatology 1990 criteria for the classification of giant cell arteritis. Arthritis Rheum 1990.

15 Murchison AP, Gilbert ME, Bilyk JR, et al. Validity of the American College of Rheumatology criteria for the diagnosis of giant cell arteritis. Am J Ophthalmol 2012;154:722-9.

16 Rao JK. Limitations of the 1990 American College of Rheumatology classification criteria in the diagnosis of vasculitis. Ann Intern Med 1998;129:345.

17 Diamantopoulos AP, Haugeberg G, Lindland A, et al. The fast-track ultrasound clinic for early diagnosis of giant cell arteritis significantly reduces permanent visual impairment: towards a more effective strategy to improve clinical outcome in giant cell arteritis? Rheumatology (UK) 2016.

18 Dejaco C, Ramiro S, Duftner C, et al. EULAR recommendations for the use of imaging in large vessel vasculitis in clinical practice. Ann Rheum Dis 2018;77:636-43.
19 Hellmich B, Agueda A, Monti S, et al. 2018 Update of the EULAR recommendations for the management of large vessel vasculitis. Ann Rheum Dis 2020.

20 Laskou F, Coath F, Mackie SL, et al. A probability score to aid the diagnosis of suspected giant cell arteritis. Clin Exp Rheumatol 2019.

21 Stone JH, Tuckwell K, Dimonaco S, et al. Trial of tocilizumab in giant-cell arteritis. N Engl J Med 2017;377:317-28.

22 Schmidt WA, Kraft HE, Vorpahl K, et al. Color duplex ultrasonography in the diagnosis of temporal arteritis. $N$ Engl J Med 1998;337:1336-42.

23 Chrysidis S, Duftner C, Dejaco C, et al. Definitions and reliability assessment of elementary ultrasound lesions in giant cell arteritis: a study from the OMERACT large vessel vasculitis ultrasound working group. RMD Open 2018.

24 Aschwanden M, Daikeler T, Kesten F, et al. Temporal artery compression sign - a novel ultrasound finding for the diagnosis of giant cell arteritis. Ultraschall Der Medizin 2013.

25 Aschwanden M, Imfeld S, Staub D, et al. The ultrasound compression sign to diagnose temporal giant cell arteritis shows an excellent interobserver agreement. Clin Exp Rheumatol 2015.

26 Schäfer VS, Juche A, Ramiro S, et al. Ultrasound cut-off values fo intima-media thickness of temporal, facial and axillary arteries in giant cell arteritis. Rheumatology (UK) 2017.

27 Van der Geest KSM, Borg F, Kayani A, et al. Novel ultrasonographic halo score for giant cell arteritis: assessment of diagnostic accuracy and association with ocular ischaemia. Ann Rheum Dis 2019.

28 Huizinga TWJ, Machold KP, Breedveld FC, et al., Criteria for early rheumatoid arthritis: from Bayes' law revisited to new thoughts on pathogenesis. Arthritis Rheum 2002;46:1155-9.

29 Luqmani R, Lee E, Singh S, et al. The role of ultrasound compared to biopsy of temporal arteries in the diagnosis and treatment of giant cell arteritis (TABUL): a diagnostic accuracy and cost-effectiveness study. Health Technol Assess (Rockv) 2016;20:1-238.

30 Sebastian A, Van der Geest KSM, Coath F, et al. Halo score (tempora artery, its branches and axillary artery) as a diagnostic, prognostic and disease monitoring tool for giant cell arteritis (GCA). BMC Rheumatology 2020; 4: Article number: 35.

31 Monti S, Ponte C, Pereira C, et al. The impact of disease extent and severity detected by quantitative ultrasound analysis in the diagnosis and outcome of giant cell arteritis. Rheumatology 2019.

32 Terslev L, Naredo E, Aegerter P, et al. Scoring ultrasound synovitis in rheumatoid arthritis: a EULAR-OMERACT ultrasound taskforce-part 2: reliability and application to multiple joints of a standardised consensus-based scoring system. RMD Open 2017;3:e000427. 